\title{
The vasodilatory mechanism of nitric oxide and hydrogen sulfide in the human mesenteric artery in patients with colorectal cancer
}

\author{
AWAT Y. HASSAN ${ }^{1}$, ISMAIL M. MAULOOD ${ }^{1}$ and ABBAS SALIHI ${ }^{1,2}$ \\ ${ }^{1}$ Department of Biology, College of Science, Salahaddin University-Erbil; ${ }^{2}$ Department of Medical Analysis, \\ Faculty of Science, Tishk International University, Erbil, Kurdistan Region 44001, Iraq
}

Received March 10, 2020; Accepted August 19, 2020

DOI: $10.3892 /$ etm.2021.9646

\begin{abstract}
Recent studies have focused on the role of gasotransmitters in cancer progression and prevention. Therefore, the current study was designed to explore the vasodilator activity of $\mathrm{NO}$ and $\mathrm{H}_{2} \mathrm{~S}$ in the human mesenteric arteries of patients with colorectal cancer $(\mathrm{CRC})$ via the activation of $\mathrm{K}^{+}$ channels. A total of two sets of experiments were established for the current investigation. Blood samples from patients with CRC were obtained to detect serum levels of endocan and malondialdehyde (MDA). The role of $\mathrm{K}^{+}$channels in mediating the vasodilation of the human mesenteric artery in response to sodium nitroprusside (SNP) and sodium disulfide $\left(\mathrm{Na}_{2} \mathrm{~S}\right)$ was assessed. The level of serum endocan was indicated to be decreased in patients with CRC compared with healthy individuals, while the level of serum MDA remained unaltered between groups. The arterial rings pre-contracted with norepinephrine were first relaxed by the cumulative addition of increasing concentrations of either SNP $(30 \mathrm{nM}-30 \mu \mathrm{M})$ or (1-6 mM). Maximal relaxation rates were then calculated at $15 \mathrm{~min}$ intervals for $60 \mathrm{~min}$. Pre-incubation of arterial rings for 20 min with individual $\mathrm{K}^{+}$channel blockers was indicated to significantly reduce SNP- and $\mathrm{Na}_{2} \mathrm{~S}$-induced relaxation at different time points. Pre-treatment of L-nitro-arginine methyl ester did not alter vasodilation that was induced by $\mathrm{Na}_{2} \mathrm{~S}$. Furthermore, vasodilation of the CRC mesenteric artery was not altered by the synergistic application of $\mathrm{SNP}$ and $\mathrm{Na}_{2} \mathrm{~S}$, while pre-incubation of arterial rings with D,L-propargylglycine significantly enhanced vasodilation induced by SNP. These results indicated that endothelial dysfunction and oxidative stress do not serve roles in the pathogenesis of CRC. The dilatory mechanisms of $\mathrm{NO}$ and $\mathrm{H}_{2} \mathrm{~S}$ in mesenteric arteries of patients with $\mathrm{CRC}$ were $\mathrm{K}^{+}$channel- and time-dependent,
\end{abstract}

Correspondence to: Dr Abbas Salihi, Department of Biology, College of Science, Salahaddin University-Erbil, Erbil-Kirkuk Road, Erbil, Kurdistan Region 44001, Iraq

E-mail: abbas.salihi@su.edu.krd

Key words: nitric oxide, hydrogen sulfide, mesenteric arteries, potassium channels, colorectal cancer and the activity of cystathionine $\gamma$-lyase enzyme inhibited the ability of exogenous NO in vasodilation processes.

\section{Introduction}

Globally, colorectal cancer (CRC) is the third most frequently detected neoplasm and the second leading cause of cancerassociated mortality, with $>1.8$ million new CRC cases and 881,000 deaths being reported globally in 2018, with $\sim 1$ death per 10 confirmed cases $(1,2)$. While the incidence of CRC in Middle Eastern countries is low (3), there is a higher annual incidence rate of CRC in the Kurdistan region of Iraq with an estimated 38-61.7 cases/100,000 people from 2006 to 2014. $\mathrm{CRC}$ is the fourth most widespread cancer in males and females residing in this province, causing $\sim 8.6 \%$ mortality of the total annual fatalities in this region (4). There is strong evidence that $\mathrm{CRC}$ is the most common type of adenocarcinoma in this region (5).

Commonly endogenous gasotransmitters that are used are $\mathrm{NO}, \mathrm{CO}$ and $\mathrm{H}_{2} \mathrm{~S}$ (6). These small molecules of gas, which have limited concentrations and particular functions, are endogenously and enzymatically generated (7). NO is produced from $\mathrm{L}$-arginine by $\mathrm{NO}$ synthase $(8,9)$, while $\mathrm{H}_{2} \mathrm{~S}$ is synthesized from L-cysteine by both cystathionine $\beta$-synthase and cystathionine $\gamma$-lyase (CSE), or mercaptopyruvate sulfurtransferase $(10,11)$. The aforementioned gaseous molecules modulate different biological pathways and functions such as SMC relaxation, at physiologically relevant concentrations (6) by opening a number of membrane ion channels (12). NO is an essential regulator of angiogenesis (13) and vasorelaxation via the activation of guanylate cyclase and the production of cyclic guanidine monophosphate (cGMP) (14). cGMP increases endothelial $\mathrm{Ca}^{+2}$ concentration and contributes to the opening of localized $\mathrm{Ca}^{+2}$-dependent $\mathrm{K}^{+}$channels $\left(\mathrm{K}_{\mathrm{Ca}}\right)(15)$. In contrast, $\mathrm{H}_{2} \mathrm{~S}$ exerts its effects on vasodilation (16) and angiogenesis (17) via the direct activation of $\mathrm{K}_{\mathrm{ATP}}$ channels (18).

$\mathrm{NO}$ and $\mathrm{H}_{2} \mathrm{~S}$ also act synergistically or antagonistically to stimulate their downstream pathways, ranging from biosynthesis to their signaling cascade within target cells (19). NO and $\mathrm{H}_{2} \mathrm{~S}$ are mutually dependent on regulating vasodilation, angiogenesis (20) and endothelial homeostasis (21). The role of these gases in cancer remains unclear, as both exhibit tumor promotion and anti-tumor properties (22). Furthermore, NO and $\mathrm{H}_{2} \mathrm{~S}$ have been indicated to modulate a variety of cancer 
cell functions, including proliferation, invasion, metastasis and tumor angiogenesis (23). Additionally, the enzymes responsible for $\mathrm{NO}$ and $\mathrm{H}_{2} \mathrm{~S}$ production are upregulated in CRC cells and endogenously produce low-to-mid concentrations of $\mathrm{H}_{2} \mathrm{~S}$ or NO to support cell proliferation, while exogenous delivery of $\mathrm{H}_{2} \mathrm{~S}$ or NO suppresses the division of colon cancer cells (24).

Intra-tumor blood vessels are vital for tumor growth, metastasis, cancer treatment (25) and the acquisition of differential reactivity by functional mature blood vessels in the tumor micro-environment, representing an appropriate target for anti-tumor therapeutic agents (26). Cancerous cells exhibit accelerated metabolism and, therefore, demand high reactive oxygen species (ROS) concentrations to maintain high proliferation rates (27). The high level of ROS damages and/or destroys cells by oxidizing proteins, lipids and nucleic acids (28). These observations clarify that oxidative stress and cancer are closely associated (29). Several researchers are investigating the consequences of ROS and endothelial dysfunction in cancer (30-32). Based on literature reviews, to the best of our knowledge, no studies appear to have presented an association between oxidative stress, endothelial functions and vascular reactivity of $\mathrm{NO}$ and $\mathrm{H}_{2} \mathrm{~S}$ in patients with CRC. Therefore, the current study aimed to assess endocan as an endothelial functional marker and malondialdehyde (MDA) as an oxidative stress marker in patients with CRC. Additionally, the present study investigated the probable mechanisms responsible for NO- and $\mathrm{H}_{2} \mathrm{~S}$-induced vasodilation in the human mesenteric artery of patients with CRC. To elucidate these mechanisms, the possible roles of different $\mathrm{K}^{+}$channels in the vasodilation response produced by $\mathrm{NO}$ and $\mathrm{H}_{2} \mathrm{~S}$ were explored.

\section{Materials and methods}

Patients. The current study was a case-control study. For the first experiment, patients were recruited at two hospitals in Erbil, Iraq: The Oncology Department of Rizgary and Nanakaly Hospitals. Venous blood samples were taken from 44 patients (male, 24; female, 20) with different stages of CRC. Additionally, 40 healthy volunteers (male, 22; female, 18) of similar ages were recruited randomly in Erbil city as control samples. For the second experiment, colorectal tumour specimens were obtained from patients with CRC undergoing partial colectomy at Consultancy Medical City and Welfare private hospitals in Erbil. In both experiments, patients were recruited between August to November 2016 and patient's median age was 55 years old (ranged between 35-70). Patients with underlying immunodeficiency disorder or immunodeficiency state and individuals who had other co-morbid health problems which could introduce heterogeneity to the sample, such as additional acquired brain injury, arthritis, chronic obstructive pulmonary disease, asthma, diabetes mellitus, ankylosing spondylitis, connective tissue diseases and other inflammatory diseases were excluded.

The blood samples were obtained by phlebotomy under an aseptic technique. Blood was placed into a clot activator tube for serum separation. The sera were then separated under centrifugation at $448 \times \mathrm{g}$ for $5 \mathrm{~min}$ at $37^{\circ} \mathrm{C}$. Patients with an underlying immunodeficiency disorder or state of immunodeficiency, and individuals who presented with other co-morbid health problems which could introduce heterogeneity to the sample (including arthritis, asthma, diabetes mellitus, hypertension and other inflammatory diseases) were excluded.

Determination of endocan. The concentration of endocan was determined using the Human ESM1 ELISA kit (cat. no. E-EL-H1557; Elabscience, Inc.) by the Sandwich-ELISA method (33). The micro ELISA plate was pre-coated with antibodies specific to endocan. Standards or samples were added to the suitable micro ELISA plate wells and combined with the endocan-specific antibodies (Elabscience, Inc.). A biotinylated detection antibody, part of the aforementioned kit, specific for endocan and avidin-horseradish peroxidase (HRP)-conjugate and substrate were then added to each well. Only the wells that contained endocan, biotinylated detection antibodies and avidin-HRP conjugate appeared blue in color and the reaction was stopped with a $1 \mathrm{~N} \mathrm{H}_{2} \mathrm{SO}_{4}$ solution and the color turned yellow. The absorbance was measured spectrophotometrically (ELISA reader; Biotek) at a wavelength of $450 \mathrm{~nm}$.

Determination of serum MDA. MDA was determined according to the Ohkawa method (34). The procedure started by thiobarbituric acid (TBA) preparation, in which $0.66 \mathrm{~g}$ TBA was dissolved in $100 \mathrm{ml}$ of $0.05 \mathrm{M}$ of $\mathrm{NaOH}$ with simple heating at $45^{\circ} \mathrm{C}$. Trichloroacetic acetic acid (TCA) was then prepared by dissolving $17.5 \mathrm{~g} \mathrm{TCA}$ in $100 \mathrm{ml}$ of distilled water. TCA2 was prepared by dissolving $70 \mathrm{~g}$ of TCA in $100 \mathrm{ml}$ of distilled water. Finally, $150 \mathrm{ml}$ of either control or CRC patient's serum was added, $1 \mathrm{ml}$ of TCA1 was mixed for $2 \mathrm{~min}$ and placed in a boiling water bath for $15 \mathrm{~min}$ and $1 \mathrm{ml}$ of TCA2 was added and incubated for $20 \mathrm{~min}$ at $37^{\circ} \mathrm{C}$. The solution was centrifuged for $5 \mathrm{~min}$ at $448 \mathrm{x} \mathrm{g}$. The supernatant was read (Unico SpectroQuest SQ2800 UV-Visible Spectrophotometer; Unico) at $532 \mathrm{~nm}$.

\section{Myographical recording}

Vessel collection and preparation. Human mesenteric arteries were collected during surgery from patients with CRC undergoing partial colectomy. The arteries supplying blood to the tumors were dissected surgically and placed into beakers containing cold modified Krebs solution (Sigma-Aldrich; Merck KGaA) (Fig. 1) and aerated with 95\% $\mathrm{O}_{2}$ and $5 \% \mathrm{CO}_{2}$. The excess tissue and fat were removed in the laboratory and the arteries were cut into rings (length, 3-4 mm).

Recording of isometric tension. The procedure by Furchgott and Zawadzki (35) with certain modifications in the Krebs solution's concentration was followed to study the vasodilator activity of the isolated mesenteric arteries. The arterial rings were propped by two stainless steel clamps. The first clamp was attached to a hook at the underside of the organ bath and the second was connected to the force transducer through a thread to record the isometric tension of the mesenteric arteries. Data were recorded using LabChart 7.1 data acquisition software (ADInstruments, Inc.). The propped arterial rings were immersed in modified Krebs solution $(\mathrm{NaCl}$ $5.10 \mathrm{gm} / 1, \mathrm{NaHCO}_{3} 1.94 \mathrm{gm} / 1, \mathrm{MgSO}_{4} 0.686 \mathrm{gm} / 1, \mathrm{KCl}$ $2.24 \mathrm{gm} / 1, \mathrm{KH}_{2} \mathrm{PO}_{4} 0.15 \mathrm{gm} / 1, \mathrm{CaCl}_{2} 0.277 \mathrm{gm} / 1$ and $\mathrm{C}_{6} \mathrm{H}_{12} \mathrm{O}_{6}$ $2 \mathrm{gm} / \mathrm{l}$ ) and contained in a $10 \mathrm{ml}$ organ chamber. Krebs 


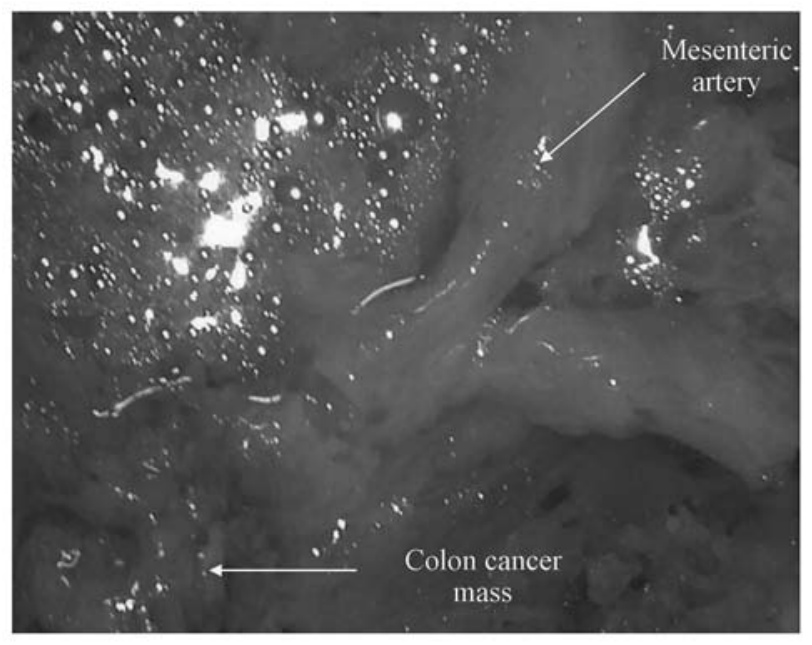

Figure 1. Mesenteric artery feeding a colon tumor.

solution was maintained at a $\mathrm{pH} 7.4$ and was constantly aerated with $95 \% \mathrm{O}_{2} 5 \% \mathrm{CO}_{2}$ at $37^{\circ} \mathrm{C}$ (panLab; Harvard Apparatus).

The mesenteric arterial rings were tensed to a stable basal strain of $4 \mathrm{gm}$ prior to being left to be equilibrated for $2 \mathrm{~h}$. The Krebs solution was replaced at 15-20 min intervals in the bath chamber until it reached stability. Experimental substances were added to the bath chambers, according to protocol. The arteries were incubated at $37^{\circ} \mathrm{C}$ with channel blockers for $20 \mathrm{~min}$ prior to pre-contraction with norepinephrine (NE; $1 \mu \mathrm{M}$; Sigma-Aldrich; Merck KGaA). Following this, relaxation occurred by bolus dose application of sodium nitroprusside (SNP; Sigma-Aldrich; Merck KGaA) or sodium sulphide $\left(\mathrm{Na}_{2} \mathrm{~S}\right.$; Hangzhou J\&H Chemical Co.).

Experimental protocol. The arterial rings, which were pre-contracted with NE, were first relaxed by the cumulative addition of either SNP (30 nM-30 $\mu \mathrm{M})$ or $\mathrm{Na}_{2} \mathrm{~S}(1-6 \mathrm{mM})$. Based on these initial experiments, the relative half-inhibitory concentration $\left(\mathrm{IC}_{50}\right)$ of SNP $(2.3 \mu \mathrm{M})$ or $\mathrm{Na}_{2} \mathrm{~S}(2.4 \mathrm{mM})$ was used to retest the ability to relax pre-contracted rings in three separate sets of experiments. In the first experiment, when the NE-induced contraction reached the uppermost value, SNP $(2.3 \mu \mathrm{M})$ or $\mathrm{Na}_{2} \mathrm{~S}(2.4 \mathrm{mM})$ was added and left for $60 \mathrm{~min}$, and the maximal relaxation rate $(\%)$ was calculated four times at each 15 min interval $(n=8)$. Following this, the role of $\mathrm{K}^{+}$channels in the progress of $\mathrm{SNP}$ and $\mathrm{Na}_{2} \mathrm{~S}$ mediated relaxation were tested via incubation at $37^{\circ} \mathrm{C}$ of the arterial rings for $20 \mathrm{~min}$ using tetraethylammonium (TEA; $1 \mathrm{mM}$ ), glibenclamide (GLIB; $0.1 \mu \mathrm{M})$, barium chloride $(\mathrm{BaCl} 2 ; 1 \mathrm{mM})$ and 4-aminopyridine (4-AP; $1 \mathrm{mM}$ ) (all supplied from Hangzhou J\&H Chemical Co.). In the second experiment, the role of endogenous NO and $\mathrm{H}_{2} \mathrm{~S}$ were tested by the pre-incubation of arterial rings with endothelial NO and CSE antagonists, L-nitro-arginine methyl ester (L-NAME; $3 \times 10^{-4} \mathrm{M}$ ) or D,L-propargylglycine (PAG; $10 \mathrm{mM}$ ) (Sigma-Aldrich; Merck KGaA), respectively for $20 \mathrm{~min}$ prior to applying SNP $(n=8)$. Finally, to examine whether the combination of $\mathrm{H}_{2} \mathrm{~S}$ and $\mathrm{NO}$ potentiates or inhibits vasorelaxation when the $\mathrm{NE}$-induced contraction reached the highest value, $\mathrm{SNP}$ and $\mathrm{Na}_{2} \mathrm{~S}$ were added simultaneously and left for $60 \min (n=8)$.
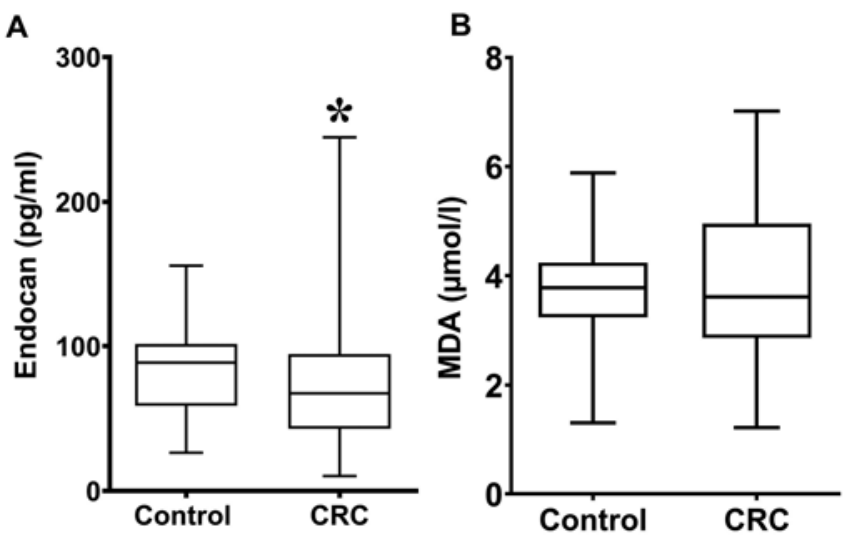

Figure 2. Comparison between (A) endocan and (B) MDA level in patients with CRC and healthy controls. Endocan was significantly decreased in patients with CRC compared with the healthy control group, while there were no significant differences MDA levels between groups. ${ }^{*} \mathrm{P}<0.05$ vs. control. MDA, malondialdehyde; CRC, colorectal cancer.

Statistical analysis. Comparisons between patients with CRC and healthy individuals were performed using a Mann-Whitney test, and values were presented as median and quartiles. Statistical analysis of myographical data was performed using a two-way ANOVA followed by Dunnett post-hoc test. Maximum relaxation responses were calculated as a percentage of the contraction produced by NE and expressed as the mean \pm standard error of the mean. The tension created by NE was defined as $0 \%$ relaxation, and the baseline tension prior to the addition of $\mathrm{NE}$ was determined as $100 \%$ relaxation.

The graphs, calculations and statistical analyses were performed using GraphPad Prism software (version 6.0; GraphPad Software, Inc.). $\mathrm{P}<0.05$ was considered to indicate a statistically significant difference.

\section{Results}

Serum endocan and MDA concentrations. Serum endocan concentration was significantly lower in patients with CRC (67.56; 43.04-94.28) compared with healthy individuals (88.68; 59-101.3; Fig. 2A). There were no significant differences in MDA concentration between patients with CRC (3.62; 2.86-4.96) and healthy individuals (3.78; 3.23-4.24; Fig. 2B).

Measurement of $I C_{50}$. SNP concentrations ranging from $30 \mathrm{nM}-30 \mu \mathrm{M}$ induced a relaxant effect on CRC mesenteric arteries following pre-contraction with $\mathrm{NE}(1 \mu \mathrm{M})$ with an $\mathrm{IC}_{50}$ value of $2.42 \pm 0.16 \mu \mathrm{M}(\mathrm{CI} 95 \%, 1.18-4.95 \mu \mathrm{M})$. The percentage of relaxation was $80.74 \pm 7.256 \% . \mathrm{Na}_{2} \mathrm{~S}$ at concentrations from 1-6 mM had a relaxant effect on mesenteric arteries of CRC pre-contracted with $\mathrm{NE}$. The calculated $\mathrm{IC}_{50}$ value was $3.54 \pm 1.07 \mathrm{mM}$ (CI 95\%, 1.4-5.68 mM) and the percentage of relaxation was $84.43 \pm 22.05 \%$. The concentration-response curve for the effect of SNP and $\mathrm{Na}_{2} \mathrm{~S}$ against $\mathrm{NE}$-mediated contractions are presented in Fig. 3A and B, respectively.

The role of $\mathrm{K}^{+}$channels in the $\mathrm{NO}$-induced relaxation. Pre-incubation of mesenteric arteries with either GLIB $(0.1 \mu \mathrm{M} ; \mathrm{n}=6)$ or TEA $(1 \mathrm{mM} ; \mathrm{n}=6)$ exhibited a significant reduction of net SNP-induced vasorelaxation in mesenteric 

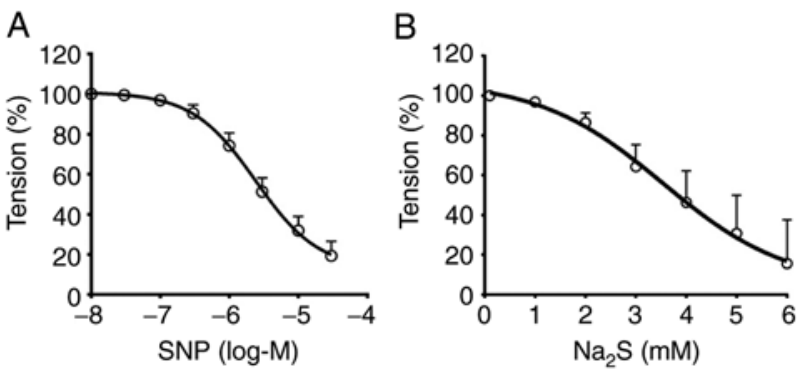

Figure 3. Cumulative dose-response curve for the vasorelaxant effects of (A) SNP (30 nM-30 $\mu \mathrm{M}$ ) and (B) $\mathrm{Na}_{2} \mathrm{~S}$ (1-6 mM) on norepinephrine (1 $\mu \mathrm{M}$ )-induced contraction in the mesenteric arteries of patients with colorectal cancer. SNP, sodium nitroprusside; $\mathrm{Na}_{2} \mathrm{~S}$, sodium sulfide.

arteries at all-time points (Fig. 4). In contrast, vasorelaxation reduction by $\mathrm{BaCl}_{2}(1 \mathrm{mM} ; \mathrm{n}=6)$ and 4 -AP $(1 \mathrm{mM} ; \mathrm{n}=6)$ was significant for $15-45 \mathrm{~min}$; however, reduction was not significant at 60 min compared with the SNP treatment group.

The role of $\mathrm{K}^{+}$channels in the $\mathrm{H}_{2} \mathrm{~S}$-induced relaxation. The impairment of $\mathrm{Na}_{2} \mathrm{~S}$-inducing relaxation in mesenteric arteries was significantly sustained at time points 30, 45 and 60 mins following 4-AP incubation $(n=6$; Fig. 5). GLIB $(n=6)$ and $\mathrm{BaCl}_{2}(\mathrm{n}=6)$ reduced vasorelaxation responses produced by $\mathrm{Na}_{2} \mathrm{~S}$ only at time point $30 \mathrm{~min}$. In contrast, TEA failed to ameliorate the vasorelaxation response of $\mathrm{Na}_{2} \mathrm{~S}$.

Interaction effects of $\mathrm{SNP}$ and $\mathrm{Na}_{2} \mathrm{~S}$. The combination of SNP and $\mathrm{Na}_{2} \mathrm{~S}$ did not significantly alter the relaxation responses at any time point compared with the relaxation induced by the application of SNP or $\mathrm{Na}_{2} \mathrm{~S}$ alone (Fig. 6A). Additionally, pre-incubation of the arterial rings with L-NAME $(n=6)$ did not significantly change the extent of $\mathrm{Na}_{2} \mathrm{~S}$-induced relaxation at any time point compared with the NasS treatment group (Fig. 6B). However, treating the mesenteric arterial rings with PAG $(n=6)$ significantly increased vasorelaxation induced by the SNP at all-time points (Fig. 6C).

\section{Discussion}

The current study revealed that the endothelium cells of patients with CRC were functioning normally since the levels of serum endocan, which is an endothelial cell marker, were significantly decreased compared with the controls (36). In this regard (37-39), the reduction of endocan may be associated with chemotherapy, VEGF receptor-2 kinase inhibitor treatment or the downregulation of endocan expression, indicating that the expression of endocan is associated with the development and differentiation of CRC (36). Furthermore, it has been demonstrated that endocan is associated with colon tumor size, depth of invasion, lymph node metastasis, distant metastasis and Dukes' staging (40). In addition to endocan, there has been a growing interest in MDA as a marker of oxidative stress in the progression of cancer (41). The present investigation demonstrated that there were no changes in the serum MDA levels in patients with CRC compared with controls. This is in contrast to a previous study that reported a considerable elevation in serum MDA levels in patients with CRC (42). Subramanyam et al (43) reported that chemotherapeutics

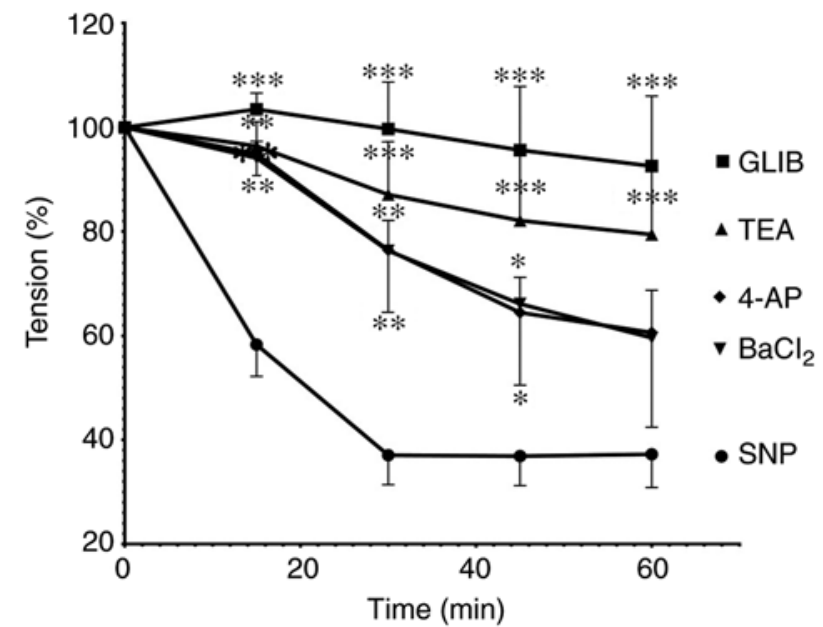

Figure 4. Time-dependent change of relaxation responses to SNP in mesenteric arteries preincubated with GLIB $(10 \mu \mathrm{M})$, TEA $(1 \mathrm{mM}), 4-\mathrm{AP}(1 \mathrm{mM})$ and $\mathrm{BaCl}_{2}(1 \mathrm{mM})$. SNP-induced vasorelaxation was significantly inhibited by GLIB, TEA, 4-AP and $\mathrm{BaCl}_{2}$ pretreatment. ${ }^{*} \mathrm{P}<0.05,{ }^{* *} \mathrm{P}<0.01$ and ${ }^{* * *} \mathrm{P}<0.001$ vs. the SNP treatment group. SNP, sodium nitroprusside; GLIB, glibenclamide; TEA, tetraethylammonium; 4-AP, 4-aminopyridine; $\mathrm{BaCl}_{2}$, barium chloride.

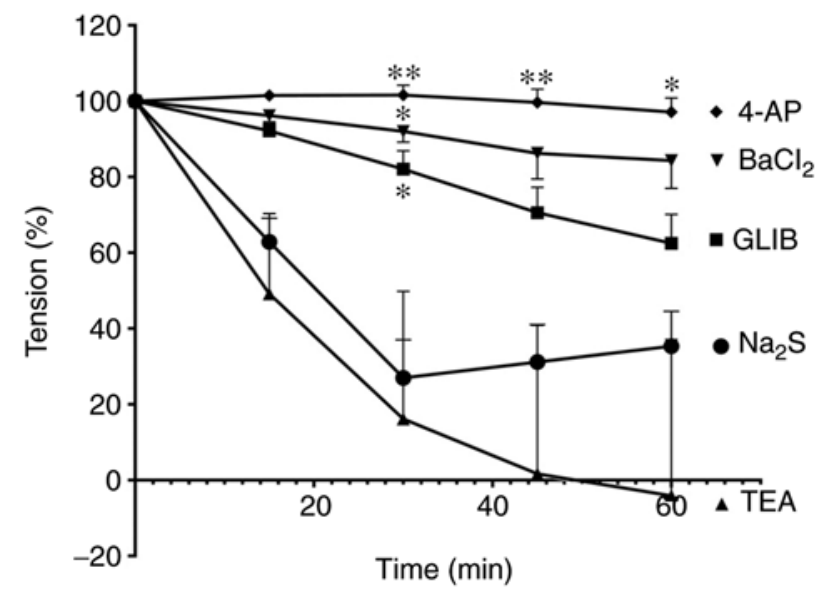

Figure 5. Time-dependent change of relaxation responses to $\mathrm{Na}_{2} \mathrm{~S}$ in mesenteric arteries preincubated with 4 -AP $(1 \mathrm{mM}), \mathrm{BaCl}_{2}(1 \mathrm{mM})$, GLIB $(10 \mu \mathrm{M})$ and TEA $(1 \mathrm{mM})$. TEA had no significant effect on $\mathrm{Na}_{2} \mathrm{~S}$-induced time-dependent arterial relaxation. $\mathrm{Na}_{2} \mathrm{~S}$-induced vasorelaxation was significantly inhibited by $4-\mathrm{AP}, \mathrm{BaCl}_{2}$ and GLIB pretreatment. ${ }^{*} \mathrm{P}<0.05$ and ${ }^{* *} \mathrm{P}<0.01$ vs. the $\mathrm{Na}_{2} \mathrm{~S}$ treatment group. $\mathrm{Na}_{2} \mathrm{~S}$, sodium sulfide; 4-AP, 4-aminopyridine; $\mathrm{BaCl}_{2}$, barium chloride; GLIB, glibenclamide; TEA, tetraethylammonium.

normalized oxidative stress in patients with CRC. Collectively, these results indicated that the arteries in patients with CRC were intact and that their endothelia were functioning properly.

Furthermore, the current study demonstrated that SNP markedly relaxed mesenteric arteries in patients with CRC. A previous study by (44) recorded $69 \%$ relaxation in the mesenteric arteries in experimental rats compared with the control group, while a relaxation of $103 \%$ was recorded in a study investigating human arm veins (45). To investigate the mechanism of SNP-induced relaxation, the role of $\mathrm{K}^{+}$channels was investigated in the mesenteric arteries of patients with CRC.

The results of the present study revealed that $\mathrm{K}^{+}$channels exhibited a significant role of SNP-induced relaxation in 

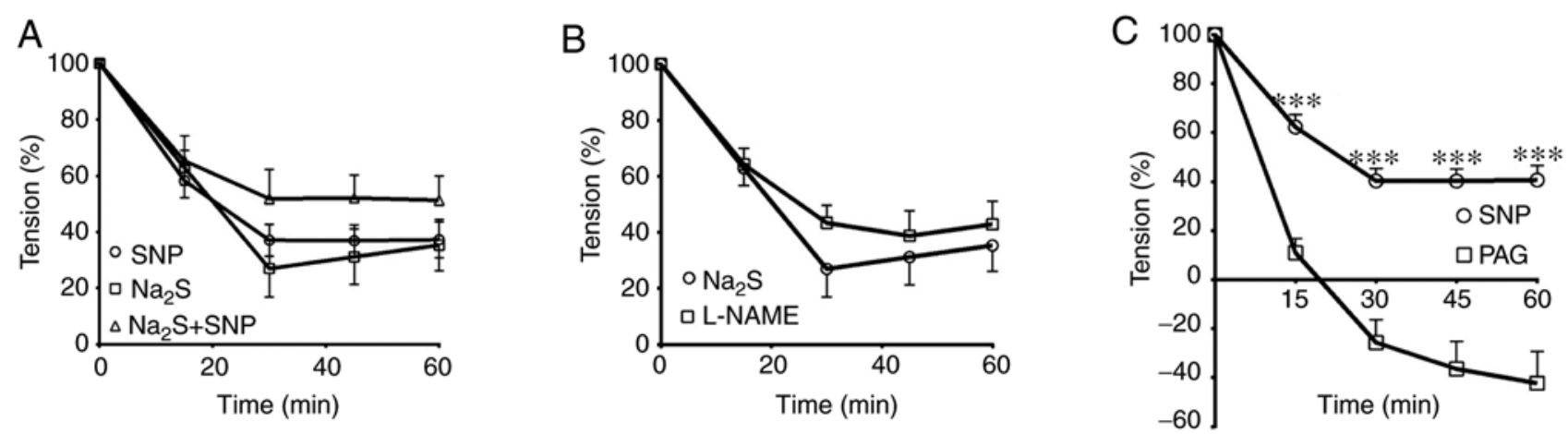

Figure 6. Combined effect of SNP and $\mathrm{Na}_{2} \mathrm{~S}$ on the time-dependent relaxation responses of the mesenteric arteries precontracted with norepinephrine. (A) Combination of SNP and $\mathrm{Na}_{2} \mathrm{~S}$ did not significantly alter time-dependent relaxation compared with SNP or $\mathrm{Na}_{2} \mathrm{~S}$ alone. (B) L-NAME (3x10-4 M) did not have a significant effect on $\mathrm{Na}_{2} \mathrm{~S}$-induced time-dependent relaxation. (C) SNP-induced relaxation was significantly increased by PAG (10 mM) pretreatment. ${ }_{* * * *} \mathrm{P}<0.001$ vs. the SNP treatment group. SNP, sodium nitroprusside; $\mathrm{Na}_{2} \mathrm{~S}$, sodium sulfide; L-NAME, L-nitro-arginine methyl ester; PAG, D, L-propargylglycine.

mesenteric arteries following pre-treatment with TEA, GLIB, $\mathrm{BaCl}_{2}$ or 4-AP. All of these significantly inhibited vasodilation. A previous study demonstrated that $\mathrm{NO}$ activated several $\mathrm{K}^{+}$ channels of the small muscle cells (SMCs) of mesenteric and cerebral arteries in rats and rabbits, including ATP-sensitive $\mathrm{K}^{+}$channels, and induced membrane hyperpolarization by lowering $\left[\mathrm{Ca}^{2+}\right]_{\mathrm{i}}$ levels via the inhibition of $\mathrm{Ca}^{2+}$ influx or $\mathrm{Ca}^{2+}$ release from intracellular storage (46). Furthermore, NO hyperpolarized arterial SMCs via the activation of both $\mathrm{K}_{\mathrm{V}}$ and $\mathrm{K}_{\mathrm{Ca}}$ channels on vascular SMCs (VSMCs) in the rat superior mesenteric, coronary, cerebral and large arteries (47-49) through a cGMP-dependent mechanism, subsequently inhibiting the depolarization of the evoked membrane and upsurge in $\left[\mathrm{Ca}^{2+}\right]_{\mathrm{i}}(50)$. The data obtained are compatible with earlier findings, where it was observed that $\mathrm{NO}$ regulated VSMC $\mathrm{K}_{\mathrm{IR}}$ currents (51). In contrast, Hempelmann et al (52) reported that neither 4-AP nor $\mathrm{BaCl}_{2}$ modulated $\mathrm{NO}$-induced relaxation in the rat basilar artery. This conclusion indicated that NO may exert vasodilation, possibly by opening different $\mathrm{K}^{+}$channels. Consequently, it can be concluded that $\mathrm{K}^{+}$channels serves a crucial role in the vasodilation mechanism of NO.

To the best of our knowledge, in terms of the influence of $\mathrm{Na}_{2} \mathrm{~S}$ on arterial relaxation, the current study was the first to observe the potency of $\mathrm{Na}_{2} \mathrm{~S}$ in relaxing the mesenteric arteries of patients with CRC. The present study demonstrated that this relaxation was dependent on the activation of $\mathrm{K}_{\mathrm{ATP}}$ and $\mathrm{K}_{\mathrm{V}}$ channels. The importance of $\mathrm{K}_{\text {АTP }}$ channel activation has been observed in the mesenteric arteries of the human colon (53), rat arterial smooth muscle (54) and human mammary arteries (55). The latter mechanism occurred either through the hyperpolarization of SMC membranes, which may close voltage-gated $\mathrm{Ca}^{2+}$ channels (56), or through channel protein sulfhydration (16). On the other hand (53), concluded that $\mathrm{H}_{2} \mathrm{~S}$ relaxed pre-contracted human mesenteric arterial rings in a concentration-dependent assay. Similarly, $\mathrm{H}_{2} \mathrm{~S}$ induced vasorelaxation in rat aortas, which was diminished by KCNQ-type $\mathrm{K}_{\mathrm{V}}$ channel blockage (57).

In contrast, it has previously been shown that $\mathrm{K}_{\mathrm{ATP}}$ channels do not mediate $\mathrm{H}_{2} \mathrm{~S}$-induced relaxation in the guinea-pig ileum or the trout urinary bladder (58). Previous studies have reported that $\mathrm{K}_{\mathrm{IR}}$ channels weakly participate in the relaxation of mesenteric arteries in patients CRC and that the mechanism of relaxation in rat aortas was mainly mediated by the stimulation of $\mathrm{K}_{\mathrm{IR}}$ channels and subsequent $\mathrm{K}_{\mathrm{IR}}$-dependent hyperpolarization from endothelium to the SMCs (59-61).

However, $\mathrm{H}_{2} \mathrm{~S}$ was demonstrated to activate $\mathrm{BK}_{\mathrm{Ca}}(62)$, $\mathrm{IK}_{\mathrm{Ca}}$ and $\mathrm{SK}_{\mathrm{Ca}}$ channels in endothelial cells (16) and $\mathrm{BK}_{\mathrm{Ca}}$ channels in SMCs of mesenteric arteries (62) and cerebral arterioles (63). The results of the present study reported that TEA did not alter the vasodilation of mesenteric arteries induced by $\mathrm{Na}_{2} \mathrm{~S}$, indicating that $\mathrm{K}_{\mathrm{Ca}}$ may not be a considerable factor for $\mathrm{H}_{2} \mathrm{~S}$-induced vasorelaxation. Similar results were observed by Tang et al (64), who noted that different $\mathrm{K}_{\mathrm{Ca}}$ channel blockers were ineffective in the vascular impact of $\mathrm{H}_{2} \mathrm{~S}$. Contrary to the current results, the maximum relaxation of VSMC in rat $(16,54,59)$ and human mammary (55) arteries induced by sodium hydrogen sulfide was significantly attenuated by $\mathrm{K}_{\mathrm{Ca}}$ channel blockers. Whereas both $\mathrm{H}_{2} \mathrm{~S}$ and $\mathrm{NO}$ are vasorelaxant factors with dissimilar mechanisms of action when applied in combination (54), the results of the current study reported that the combination of SNP and $\mathrm{Na}_{2} \mathrm{~S}$ donors did not significantly alter maximum relaxation compared with the administration of SNP or $\mathrm{Na}_{2} \mathrm{~S}$ alone. The generation of a novel molecule (perhaps nitrosothiol) via the combination of $\mathrm{H}_{2} \mathrm{~S}$ and $\mathrm{NO}$ does not relax blood vessels in vitro or in vivo (65). Consequently, the formation of this unique molecule most likely signifies an approach to biological inactivation or possibly sequestration of released NO (66). In contrast, rat aortic relaxation was prolonged when the gas donors were combined (67). This synergistic action may be due to the production of S-nitrosothiol (HSNO) and nitroxyl (HNO) as the result of a chemical reaction between $\mathrm{H}_{2} \mathrm{~S}$ and nitrite (68), which releases $\mathrm{NO}$ and polysulfides, and relaxes VSMCs through soluble guanylyl cyclase activation (69).

Simultaneously, pre-incubation of L-NAME did not alter $\mathrm{Na}_{2} \mathrm{~S}$-induced relaxation. Similar results have been reported by $(70,71)$. These authors demonstrated that L-NAME did not modify the $\mathrm{Na}_{2} \mathrm{~S}$-induced relaxation in isolated porcine irides. This conclusion indicated that endogenous $\mathrm{NO}$ does not have an impact on the vasoactivity of the $\mathrm{H}_{2} \mathrm{~S}$ donor. In contrast, pre-incubation of the arterial rings of patients with CRC with PAG did increase the relaxation activity induced by the NO donor. The justification for this reaction is associated with the activity of endogenous $\mathrm{H}_{2} \mathrm{~S}$ in inhibiting the action of NO. In a 
similar manner, SNP-induced vasorelaxation in rat aortas and human internal mammary arteries was diminished by a low concentration of $\mathrm{H}_{2} \mathrm{~S}$ through the suppression of $\mathrm{NO}$ action or inhibition of NO synthase $(56,64)$.

In 2015, Kashfi et al (72) investigated the effect of a $\mathrm{NO}$ - and $\mathrm{H}_{2} \mathrm{~S}$-releasing hybrid on the growth properties of various (HCT116 and NCM356) CRC cell lines. Additionally, in 2017, Oláh et al (24) explored the expression of NO- and $\mathrm{H}_{2} \mathrm{~S}$-generating enzymes in primary CRC tissues and the HCT116 CRC cell line. A limitation of the current study is that only the vasodilatory activity of $\mathrm{NO}$ and $\mathrm{H}_{2} \mathrm{~S}$ donors in the human mesenteric artery of patients with CRC was investigated. Therefore, future studies should focus on assessing the molecular signaling pathways in CRC tissues and cell lines to provide a more comprehensive model of the expression patterns of $\mathrm{NO}$ and $\mathrm{H}_{2} \mathrm{~S}$ enzymes.

In conclusion, low endocan and normal MDA levels in patients with CRC revealed that endothelial dysfunction and oxidative stress were not involved in the pathogenesis of CRC. Furthermore, the mechanism of $\mathrm{NO}$ and $\mathrm{H}_{2} \mathrm{~S}$-induced mesenteric artery vasodilation was time- and $\mathrm{K}^{+}$channel-dependent, as NO dilates mesenteric arteries via the activation of $\mathrm{K}_{\mathrm{ATP}}, \mathrm{K}_{\mathrm{Ca}}$, $\mathrm{K}_{\mathrm{IR}}$ and $\mathrm{K}_{\mathrm{V}}$ channels, while the vasodilation activity of $\mathrm{H}_{2} \mathrm{~S}$ is due to the modulation of $\mathrm{K}_{\mathrm{ATP}}$ and $\mathrm{K}_{\mathrm{V}}$ channels. Additionally, $\mathrm{NO}$ and $\mathrm{H}_{2} \mathrm{~S}$ interacted at the enzyme level and the activity of the CSE enzyme inhibited the ability of exogenous NO in the vasodilatation process.

\section{Acknowledgements}

The authors would like to thank Dr Saeb Gailany and Dr Imad at the at Consultancy Medical City and Welfare hospitals (Kurdistan region of Iraq, Iraq) for providing the human CRC specimens. Finally, the authors would like to thank Dr Karim Khoshnaw (Salahaddin University-Erbil), Mrs. Lynne Colley (Soran University), Mrs. Marley Tinnock (UNDP) and Mr. Kumar Tiku (UNDP) for their diligent proofreading of this article.

\section{Funding}

No funding was received.

\section{Availability of data and materials}

The datasets used and/or analyzed during the present study are available from the corresponding author on reasonable request.

\section{Authors' contributions}

AYH performed the experiments and co-wrote the manuscript. IMM designed the experiments and co-wrote the paper. ASS designed the experiments, analyzed data and co-wrote the manuscript. All authors read and approved the final manuscript.

\section{Ethics approval and consent to participate}

The present study was authorized and approved by the Human Ethics Committee of Salahaddin University-Erbil. Patients provided written informed consent.

\section{Patient consent for publication}

All patients provided written informed consent for the publication of data in the current study.

\section{Competing interests}

The authors declare that they have no competing interests.

\section{References}

1. Bray F, Ferlay J, Soerjomataram I, Siegel RL, Torre LA and Jemal A: Global cancer statistics 2018: GLOBOCAN estimates of incidence and mortality worldwide for 36 cancers in 185 countries. CA Cancer J Clin 68: 394-424, 2018.

2. Arafa MA and Farhat KH: Recent diagnostic procedures for colorectal cancer screening: Are they cost-effective? Arab J Gastroenterol 18: 136-139, 2017.

3. Alhurry AM, Rezaianzadeh A, Rahimikazerooni S, Abd-Zaid Akool M, Bahrami F, Saeedeh Shahidinia S and Pourahmad M: A review of the incidence of colorectal cancer in the Middle East. Ann Colorectal Res 5: e46292, 2017.

4. Khoshnaw N, Mohammed HA and Abdullah DA: Patterns of cancer in Kurdistan-results of eight years cancer registration in sulaymaniyah Province-Kurdistan-Iraq. Asian Pac J Cancer Prev 16: 8525-8531, 2016.

5. Hamza $\mathrm{H}$ and Rasul K: The epidemiology of colorectal cancer in Erbil. Cancer Sci Res 4: 1-7, 2018.

6. Wang R: Two's company, three's a crowd: Can H2S be the third endogenous gaseous transmitter? FASEB J 16: 1792-1798, 2002.

7. Yang G, Sener A, Ji Y, Pei Y and Pluth MD: Gasotransmitters in biology and medicine: Molecular mechanisms and drug targets. Oxid Med Cell Longev 2016: 4627308, 2016.

8. Moncada S, Palmer RM and Higgs EA: Biosynthesis of nitric oxide from L-arginine. A pathway for the regulation of cell function and communication. Biochem Pharmacol 38: 1709-1715, 1989.

9. Palmer RM, Rees DD, Ashton DS and Moncada S: L-arginine is the physiological precursor for the formation of nitric oxide in endothelium-dependent relaxation. Biochem Biophys Res Commun 153: 1251-1256, 1988.

10. Kabil O and Banerjee R: Enzymology of H2S biogenesis, decay and signaling. Antioxid Redox Signal 20: 770-782, 2014.

11. Filipovic MR: Persulfidation (S-sulfhydration) and H2S. Handb Exp Pharmacol 230: 29-59, 2015.

12. Wang R, Cheng Y and Wu L: The role of hydrogen sulfide as an endogenous vasorelaxant factor. In: Signal transduction and the gasotransmitters. Wang R (ed). Humana Press, pp323-332, 2004.

13. Nematollahi S, Nematbakhsh M, Haghjooyjavanmard S, Khazaei $M$ and Salehi M: Inducible nitric oxide synthase modulates angiogenesis in ischemic hindlimb of rat. Biomed Pap Med Fac Univ Palacky Olomouc Czech Repub 153: 125-129, 2009.

14. Lüscher TF, Boulanger CM, Dohi Y and Yang ZH: Endothelium-derived contracting factors. Hypertension 19: 117-130, 1992.

15. Chadha PS, Liu L, Rikard-Bell M, Senadheera S, Howitt L, Bertrand RL, Grayson TH, Murphy TV and Sandow SL: Endothelium-dependent vasodilation in human mesenteric artery is primarily mediated by myoendothelial gap junctions intermediate conductance calcium-activated $\mathrm{K}+$ channel and nitric oxide. J Pharmacol Exp Ther 336: 701-708, 2011.

16. Mustafa AK, Sikka G, Gazi SK, Steppan J, Jung SM, Bhunia AK, Barodka VM, Gazi FK, Barrow RK, Wang R, et al: Hydrogen sulfide as endothelium-derived hyperpolarizing factor sulfhydrates potassium channels. Circ Res 109: 1259-1268, 2011.

17. Szabó C and Papapetropoulos A: Hydrogen sulphide and angiogenesis: Mechanisms and applications. Br J Pharmacol 164: 853-865, 2011.

18. Tang G, Wu L, Liang W and Wang R: Direct stimulation of K(ATP) channels by exogenous and endogenous hydrogen sulfide in vascular smooth muscle cells. Mol Pharmacol 68: 1757-1764, 2005.

19. Coletta C, Papapetropoulos A, Erdelyi K, Olah G, Módis K, Panopoulos P, Asimakopoulou A, Gerö D, Sharina I, Martin E and Szabo C: Hydrogen sulfide and nitric oxide are mutually dependent in the regulation of angiogenesis and endothelium-dependent vasorelaxation. Proc Natl Acad Sci USA 109: 9161-9166, 2012. 
20. Mistry RK and Brewer AC: Redox regulation of gasotransmission in the vascular system: A focus on angiogenesis. Free Radic Biol Med 108: 500-516, 2017.

21. Hu Q, Wu D, Ma F, Yang S, Tan B, Xin H, Gu X, Chen X, Chen S, Mao Y and Zhu YZ: Novel angiogenic activity and molecular mechanisms of ZYZ-803, a slow-releasing hydrogen sulfide-nitric oxide hybrid molecule. Antioxid Redox Signal 25: 498-514, 2016.

22. Kashfi K: The dichotomous role of $\mathrm{H}_{2} \mathrm{~S}$ in cancer cell biology? Deja vu all over again. Biochem Pharmacol 149: 205-223, 2018.

23. Szabo C: Gasotransmitters in cancer: From pathophysiology to experimental therapy. Nat Rev Drug Discov 15: 185-203, 2016.

24. Oláh G, Módis K, Törö G, Hellmich MR, Szczesny B and Szabo C: Role of endogenous and exogenous nitric oxide, carbon monoxide and hydrogen sulfide in HCT116 colon cancer cell proliferation. Biochem Pharmacol 149: 186-204, 2017.

25. Kather JN, Zöllner FG, Schad LR, Melchers SM, Sinn HP Marx A, Gaiser T and Weis CA: Identification of a characteristic vascular belt zone in human colorectal cancer. PLoS One 12 e0171378, 2017.

26. Sonveaux P: Provascular strategy: Targeting functional adaptations of mature blood vessels in tumors to selectively influence the tumor vascular reactivity and improve cancer treatment. Radiother Oncol 86: 300-313, 2008.

27. Sosa V, Moline T, Somoza R, Paciucci R, Kondoh H and ME LL: Oxidative stress and cancer: An overview. Ageing Res Rev 12: 376-390, 2013.

28. Gill JG, Piskounova E and Morrison SJ: Cancer, oxidative stress, and metastasis. Cold Spring Harb Symp Quant Biol 81: 163-175, 2016.

29. Reuter S, Gupta SC, Chaturvedi MM and Aggarwal BB Oxidative stress, inflammation, and cancer: How are they linked? Free Radic Biol Med 49: 1603-1616, 2010.

30. Perše M: Oxidative stress in the pathogenesis of colorectal cancer: Cause or consequence? Biomed Res Int 2013: 725710, 2013.

31. Perillo B, Di Donato M, Pezone A, Di Zazzo E, Giovannelli P, Galasso G, Castoria G and Migliaccio A: ROS in cancer therapy: The bright side of the moon. Exp Mol Med 52: 192-203, 2020.

32. Hsu T, Nguyen-Tran HH and Trojanowska M: Active roles of dysfunctional vascular endothelium in fibrosis and cancer. J Biomed Sci 26: 86, 2019.

33. Orbegozo D, Rahmania L, Irazabal M, Mendoza M, Annoni F, De Backer D, Creteur J and Vincent JL: Endocan as an early biomarker of severity in patients with acute respiratory distress syndrome. Ann Intensive Care 7: 93, 2017.

34. Ohkawa H, Ohishi $\mathrm{N}$ and Yagi K: Assay for lipid peroxides in animal tissues by thiobarbituric acid reaction. Anal Biochem 95 351-358, 1979

35. Furchgott RF and Zawadzki JV: The obligatory role of endothelial cells in the relaxation of arterial smooth muscle by acetylcholine. Nature 288: 373-376, 1980.

36. Zuo L, Zhang SM, Hu RL, Zhu HQ, Zhou Q, Gui SY, Wu Q and Wang Y: Correlation between expression and differentiation of endocan in colorectal cancer. World J Gastroenterol 14 4562-4568, 2008.

37. Hatfield KJ, Lassalle $P$, Leiva RA, Lindås R, Wendelboe $\emptyset$ and Bruserud $\varnothing$ : Serum levels of endothelium-derived endocan are increased in patients with untreated acute myeloid leukemia. Hematology 16: 351-356, 2011

38. Yang J, Yang Q, Yu S and Zhang X: Endocan: A new marker for cancer and a target for cancer therapy. Biomed Rep 3: 279-283, 2015.

39. Delehedde M, Devenyns L, Maurage CA and Vives RR: Endocan in cancers: A lesson from a circulating dermatan sulfate proteoglycan. Int J Cell Biol 2013: 705027, 2013.

40. Pardo LA and Stuhmer W: The roles of $\mathrm{K}(+)$ channels in cancer Nat Rev Cancer 14: 39-48, 2014.

41. Gönenç A, Erten D, Aslan S, Akinci M, Simşek B and Torun M: Lipid peroxidation and antioxidant status in blood and tissue of malignant breast tumor and benign breast disease. Cell Biol Int 30: 376-380, 2006

42. Skrzydlewska E, Sulkowski S, Koda M, Zalewski B, Kanczuga-Koda L and Sulkowska M: Lipid peroxidation and antioxidant status in colorectal cancer. World J Gastroenterol 11: 403-406, 2005

43. Subramanyam D, Subbaiah KV, Rajendra W and Lokanatha V: Serum selenium concentration and antioxidant activity in cervical cancer patients before and after treatment. Exp Oncol 35: 97-100, 2013.
44. Plane F, Sampson LJ, Smith JJ and Garland CJ: Relaxation to authentic nitric oxide and SIN-1 in rat isolated mesenteric arteries: Variable role for smooth muscle hyperpolarization. $\mathrm{Br}$ J Pharmacol 133: 665-672, 2001.

45. Chalon S, Tejura B, Moreno H, Urae A, Blaschke TF and Hoffman BB: Role of nitric oxide in isoprenaline and sodium nitroprusside-induced relaxation in human hand veins. Br J Clin Pharmacol 47: 91-98, 1999.

46. Brayden JE: Functional roles of $\mathrm{K}_{\mathrm{ATP}}$ channels in vascular smooth muscle. Clin Exp Pharmacol Physiol 29: 312-316, 2002.

47. Félétou M: Calcium-activated potassium channels and endothelial dysfunction: Therapeutic options? Br J Pharmacol 156: 545-562, 2009

48. Ko EA, Han J, Jung ID and Park WS: Physiological roles of K+ channels in vascular smooth muscle cells. J Smooth Muscle Res 44: 65-81, 2008.

49. Stankevicius E, Dalsgaard T, Kroigaard C, Beck L, Boedtkjer E, Misfeldt MW, Nielsen G, Schjorring O, Hughes A and Simonsen U: Opening of small and intermediate calciumactivated potassium channels induces relaxation mainly mediated by nitric-oxide release in large arteries and endothelium-derived hyperpolarizing factor in small arteries from rat. J Pharmacol Exp Ther 339: 842-850, 2011.

50. Jiang J, Thoren P, Caligiuri G, Hansson GK and Pernow J: Enhanced phenylephrine-induced rhythmic activity in the atherosclerotic mouse aorta via an increase in opening of $\mathrm{K}_{\mathrm{Ca}}$ channels: Relation to Kv channels and nitric oxide. Br J Pharmacol 128: 637-646, 1999.

51. Schubert R, Krien U, Wulfsen I, Schiemann D, Lehmann G, Ulfig N, Veh RW, Schwarz JR and Gago H: Nitric oxide donor sodium nitroprusside dilates rat small arteries by activation of inward rectifier potassium channels. Hypertension 43: 891-896, 2004.

52. Hempelmann RG, Seebeck J, Kruse ML, Ziegler A and Mehdorn HM: Role of potassium channels in the relaxation induced by the nitric oxide (NO) donor DEA/NO in the isolated rat basilar artery. Neurosci Lett 313: 21-24, 2001.

53. Materazzi S, Zagli G, Nassini R, Bartolini I, Romagnoli S, Chelazzi C, Benemei S, Coratti A, De Gaudio AR and Patacchini R: Vasodilator activity of hydrogen sulfide $(\mathrm{H} 2 \mathrm{~S})$ in human mesenteric arteries. Microvasc Res 109: 38-44, 2017.

54. Zhao W, Zhang J, Lu Y and Wang R: The vasorelaxant effect of $\mathrm{H}(2) \mathrm{S}$ as a novel endogenous gaseous K(ATP) channel opener. EMBO J 20: 6008-6016, 2001.

55. Webb GD, Lim LH, Oh VM, Yeo SB, Cheong YP, Ali MY, El Oakley R, Lee CN, Wong PS, Caleb MG, et al: Contractile and vasorelaxant effects of hydrogen sulfide and its biosynthesis in the human internal mammary artery. J Pharmacol Exp Ther 324: 876-882, 2008

56. Zhao W and Wang R: H(2)S-induced vasorelaxation and underlying cellular and molecular mechanisms. Am J Physiol Heart Circ Physiol 283: H474-H480, 2002.

57. Köhn C, Schleifenbaum J, Szijártó IA, Markó L, Dubrovska G, Huang $Y$ and Gollasch $M$ : Differential effects of cystathionine- $\gamma$-lyase-dependent vasodilatory $\mathrm{H} 2 \mathrm{~S}$ in periadventitial vasoregulation of rat and mouse aortas. PLoS One 7: e41951, 2012.

58. Teague B, Asiedu S and Moore PK: The smooth muscle relaxant effect of hydrogen sulphide in vitro: Evidence for a physiological role to control intestinal contractility. Br J Pharmacol 137: 139-145, 2002

59. Al-Magableh MR and Hart JL: Mechanism of vasorelaxation and role of endogenous hydrogen sulfide production in mouse aorta. Naunyn Schmiedebergs Arch Pharmacol 383: 403-413, 2011.

60. Doughty JM, Boyle JP and Langton PD: Blockade of chloride channels reveals relaxations of rat small mesenteric arteries to raised potassium. Br J Pharmacol 132: 293-301, 2001.

61. Salihi A: Activation of inward rectifier potassium channels in high salt impairment of hydrogen sulfide-induced aortic relaxation in rats. Physiol Pharmacol 19: 263-273, 2016.

62. Jackson-Weaver O, Osmond JM, Riddle MA, Naik JS, Gonzalez Bosc LV, Walker BR and Kanagy NL: Hydrogen sulfide dilates rat mesenteric arteries by activating endothelial large-conductance $\mathrm{Ca}^{2+}$-activated $\mathrm{K}^{+}$channels and smooth muscle $\mathrm{Ca}^{2+}$ sparks. Am J Physiol Heart Circ Physiol 304: H1446-H1454, 2013.

63. Liang GH, Xi Q, Leffler CW and Jaggar JH: Hydrogen sulfide activates $\mathrm{Ca}^{2+}$ sparks to induce cerebral arteriole dilatation. J Physiol 590: 2709-2720, 2012. 
64. Tang G, Wu L and Wang R: Interaction of hydrogen sulfide with ion channels. Clin Exp Pharmacol Physiol 37: 753-763, 2010.

65. Whiteman M, Li L, Kostetski I, Chu SH, Siau JL, Bhatia M and Moore PK: Evidence for the formation of a novel nitrosothiol from the gaseous mediators nitric oxide and hydrogen sulphide. Biochem Biophys Res Commun 343: 303-310, 2006.

66. Ali MY, Ping CY, Mok YY, Ling L, Whiteman M, Bhatia M and Moore PK: Regulation of vascular nitric oxide in vitro and in vivo; a new role for endogenous hydrogen sulphide? $\mathrm{Br}$ J Pharmacol 149: 625-634, 2006.

67. Salihi AB, Shekha MS and Al-Habib OA: Vasodilatory effects of nitric oxide, hydrogen sulfide and sulfur dioxide in rats: Time-dependent interaction study. Prog Biol Sci 6: 19-30, 2016.

68. Filipovic MR, Miljkovic JL, Nauser T, Royzen M, Klos K, Shubina T, Koppenol WH, Lippard SJ and Ivanović-Burmazović I: Chemical characterization of the smallest S-Nitrosothiol, HSNO; cellular cross-talk of H2S and S-nitrosothiols. J Am Chem Soc 134: 12016-12027, 2012.
69. Cortese-Krott MM, Fernandez BO, Santos JL, Mergia E, Grman M, Nagy P, Kelm M, Butler A and Feelisch M: Nitrosopersulfide (SSNO(-)) accounts for sustained NO bioactivity of S-nitrosothiols following reaction with sulfide. Redox Biol 2: 234-244, 2014

70. Ohia SE, Opere CA, Monjok EM, Kouamou G, Leday AM and Njie-Mbye YF: Role of hydrogen sulfide production in inhibitory action of L-cysteine on isolated porcine irides. Curr Eye Res 35: 402-407, 2010.

71. Monjok EM, Kulkarni KH, Kouamou G, McKoy M, Opere CA, Bongmba ON, Njie YF and Ohia SE: Inhibitory action of hydrogen sulfide on muscarinic receptor-induced contraction of isolated porcine irides. Exp Eye Res 87: 612-616, 2008.

72. Kashfi K, Chattopadhyay M and Kodela R: NOSH-sulindac (AVT-18A) is a novel nitric oxide- and hydrogen sulfide-releasing hybrid that is gastrointestinal safe and has potent antiinflammatory, analgesic, antipyretic, anti-platelet, and anti-cancer properties. Redox Biol 6: 287-296, 2015. 